Personalidade Acadêmica Homenageada:

Carlos Aurélio Mota de Souza (Universidade Ibirapuera - UNIB)

\title{
A RESPONSABILIDADE ADMINISTRATIVA E CIVIL DE PESSOAS JURÍDICAS PELA PRÁTICA DE ATOS CONTRA A ADMINISTRAÇÃO PÚBLICA EM FACE DA LEI N 12.846/2013 “LEI ANTICORRUPÇÃO”
}

\section{THE ADMINISTRATIVE AND CIVIL LIABILITY OF LEGAL PERSONS FOR THE PRACTICE OF ACTS AGAINST THE PUBLIC ADMINISTRATION IN THE FACE OF LAW No. 12.846 / 2013 "ANTI- CORRUPTION LAW"}

\section{HORÁCIO MONTESCHIO}

Doutor em direito pela FADISP. Mestre em Direitos da Personalidade UNICESUMAR. Professor de Direito Administrativo e Processo Administrativo do UNICURITIBA Especialista em Direito Imobiliário e Direito Processual Civil pela EPD; Processo Civil e Direito Público, pelo Instituto Brasileiro de Estudos Jurídicos- IBEJ; Direito Tributário, pela UFSC; Direito Administrativo, pelo IRFB; Direito Aplicado pela Escola da Magistratura do Estado do Paraná. Advogado. Autor da obra jurídica "Conteúdo patrimonial do direito de Imagem". Advogado.

\section{VALÉRIA JULIANA TORTATO MONTESCHIO}

Mestre em Políticas Públicas da Educação, especialista em Gestão Educacional. Graduada em Direito pela Universidade Estadual de Maringá. Graduada em Pedagogia, professora nas Faculdades POSITIVO e FAEL, autora da obra Direito da Criança e do Adolescente, advogada.

\section{GIOVANA ZANETE MONTESCHIO}

Acadêmica do Curso de Direito pelo UNICESUMAR; Integrante do centro de Apoio do Tribunal de Justiça do Estado do Paraná. 


\section{Personalidade Acadêmica Homenageada:}

\section{Carlos Aurélio Mota de Souza (Universidade Ibirapuera - UNIB)}

\section{RESUMO}

Com a entrada em vigor da Lei ํo 12.846/2013, também conhecida como Lei Anticorrupção, que entre os seus principais dispositivos buscam inovar o ordenamento jurídico pátrio ao disciplinar a responsabilidade administrativa e civil de pessoas jurídicas pela prática de atos contra a administração pública. A importância da legislação sobressai diante da busca de uma nova visão interpretativa e sancionatória com o claro objetivo de alcançar a redução da prática de atos de corrupção, tendo em vista que eliminar tão ignóbil e abjeta prática da realidade brasileira se mostra totalmente impossível. Em face do texto legal recentemente sancionado a Lei $\mathrm{n}^{\circ}$ 12.846/13 passa a exigir que as empresas públicas e privadas venham a se adaptarem às inovações propostas. Como principal consequência da "Lei Anticorrupção" encontra se obrigatoriedade de implantação de mecanismos de prevenção e planejamento estratégico, a fim de monitorarem o relacionamento com a Administração Pública, com o intuito de evitar a aplicação das severas penalidades previstas. Por sua vez, os mecanismos inseridos na Lei anticorrupção tem o escopo de controlar as práticas empresariais, bem como consolidar a integridade das práticas de relacionamento entre as empresas, as quais permitirão alçar um novo patamar de cultura cidadã e ética no âmbito empresarial, que reverterá para toda a sociedade.

PALAVRAS-CHAVE: Responsabilidade Civil e Administrativa; corrupção; complience; controle administrativo.

\section{ABSTRACT}

With the entry into force of Law No. 12,846 / 2013, also known as the Anti-Corruption Law, which among its main provisions seek to innovate the legal order of the country by disciplining the administrative and civil liability of legal entities for the practice of acts against the public administration. The importance of legislation stands out in the search for a new interpretive and sanctioning vision with the clear objective of achieving a reduction in the practice of acts of corruption, since eliminating such ignoble and abject practice of the Brazilian reality is totally impossible. In light of the 


\section{Personalidade Acadêmica Homenageada:}

Carlos Aurélio Mota de Souza (Universidade Ibirapuera - UNIB)

recently enacted legal text, Law No. 12.846 / 13 requires that public and private companies adapt to the proposed innovations. As a main consequence of the "AntiCorruption Law", it is mandatory to implement prevention and strategic planning mechanisms in order to monitor the relationship with the Public Administration, in order to avoid the application of severe penalties. In turn, the mechanisms included in the Anti-Corruption Law have the scope to control business practices, as well as to consolidate the integrity of the relationship practices between companies, which will allow to raise a new level of citizen culture and ethics in the business sphere, which will revert for the whole society.

KEYWORDS: Civil and Administrative Liability; corruption; complience; administrative control.

\section{INTRODUÇÃO}

Um dos maiores males que afeta o mundo, mas especialmente a República Federativa do Brasil, é a prática da Corrupção'. Os malefícios causados pela prática de seus atos causam prejuízos de forma inquestionável a todos. Cabe ressaltar o fato de que a prática de atos de corrupção não serão eliminados de forma total em nosso país, mas é possível que com medidas legislativas sólidas e consistentes, aliados a aspectos de atuação ativa das instituições, as quais façam a impor e fazer cumprir as

\footnotetext{
${ }^{1}$ Corrupção é o efeito ou ato de corromper alguém ou algo, com a finalidade de obter vantagens em relação aos outros por meios considerados ilegais ou ilícitos. Etimologicamente, o termo "corrupção" surgiu a partir do latim corruptus, que significa o "ato de quebrar aos pedaços", ou seja, decompor e deteriorar algo. A ação de corromper pode ser entendida também como o resultado de subornar, dando dinheiro ou presentes para alguém em troca de benefícios especiais de interesse próprio. A corrupção é um meio ilegal de se conseguir algo, sendo considerada grave crime em alguns países. Normalmente, a pratica da corrupção está relacionada com a baixa instrução política da sociedade, que muitas vezes compactua com os sistemas corruptos. A corrupção na política pode estar presente em todos os poderes do governo, como o Legislativo, Judiciário e Executivo. No entanto, a corrupção não existe apenas na política, mas também nas relações sociais humanas, como o trabalho, por exemplo. GUIMARÃES, Deocleciano Torrieri. Dicionário Universitário Jurídico. Rio de Janeiro : Rideel. 2013, p. 104.
} 


\section{Personalidade Acadêmica Homenageada:}

\section{Carlos Aurélio Mota de Souza (Universidade Ibirapuera - UNIB)}

respectivas sanções importa que teremos a redução das práticas de atos de corrupção.

No Brasil uma das medidas legislativas aptas a impor contornos mais rígidos a prática de atos de corrupção é verificado com a entrada em vigor em $1^{\circ}$ de agosto de 2013 da Lei $n^{\circ}$ 12.846, também conhecida como "Lei Anticorrupção". É por intermédio desta legislação que o Estado brasileiro busca impor sanções mais rigorosas aos praticantes de atos de corrupção. Aliado a isso, cabe ressaltar o fato de que a citada legislação traz em seu bojo expressiva carga de inovação, se inserindo entre as legislações mais avançadas do mundo, tendo como mote essencial estabelecer regras de convivência proba entre o setor público e privado.

A fonte inspiradora da legislação pátria se encontra fundamenta na constante nas legislações dos Estados Unidos da América e da Inglaterra, as quais o legislador pátrio foi abeberar sobre as boas práticas de combate a corrupção por lá feitas, sendo digno de destaque a responsabilização administrativa e civil de pessoas jurídicas pela prática de atos contra a administração pública, nacional ou estrangeira.

Cabe ressaltar e louvar a importância da "Lei Anticorrupção", ainda mais dentro de um cenário desafiador para as organizações que atuam no Brasil, em termos de criação de uma estrutura de governança corporativa, de gestão de riscos, de controles internos e mudanças na cultura da empresa. Portanto a aprovação da Lei abre uma nova frente para que o País vença aquele que é um de seus maiores problemas, a corrupção, e as empresas terão papel fundamental nessa batalha.

Muitas empresas tem deixado de atuar no Brasil em razão da excessiva burocracia estatal, que quando aplicada de forma desmedida, irracional e ilógica acaba por se tornar um campo fértil para a cultura da corrupção.

Aliado a temática central presente na Lei Anticorrupção, as boas práticas presentes nos programas de compliance apresentam-se como matéria subjacente, mas que vem a corroborar a temática envolvendo a relação honesta e correta no âmbito da Administração Pública e a iniciativa privada.

Além da atualidade do tema, o presente texto traz em seu bojo uma análise critica em face dos reiterados escândalos de corrupção, bem como realça os protestos de uma sociedade cada vez mais intolerante com tal prática. 


\section{Personalidade Acadêmica Homenageada:}

Carlos Aurélio Mota de Souza (Universidade Ibirapuera - UNIB)

Nesse sentido, objetiva-se analisar as especificidades da lei, com foco no complicance como estratégia jurídica para as organizações que terão que se adaptar a legislação, já que a adoção de um efetivo programa de controle interno que venha a previnir a corrupção no ambiente empresarial e, consequentemente, a aplicações de sansões previstas na lei.

\section{ASPECTOS RELEVANTES QUE ENVOLVEM A PRÁTICA DA CORRUPÇÃO}

O tema relacionado a corrupção não passam desapercebido dos organismos mundiais de controle. Cabe ressaltar que a corrupção vem sofrendo, pelo mundo a fora, grandes derrotas em seguimentos até então inatingível. Veja, que até pouco tempo atrás, a título exemplificativo, as matérias envolvendo organizações de comunicação e federações de futebol não sofriam qualquer fiscalização pelas suas práticas.

Os números expressivos envolvendo os eventos esportivos, especificamente praticados na América do Sul acabaram por chamar a atenção de autoridades norteamericanas a ponto de instaurar um processo judicial e culminou com a prisão da Federação brasileira de Futebol. Desta forma, searas até então imunes à fiscalização por autoridades policiais e fazendárias acabaram por desvendar práticas criminosas, as quais lesam a concorrência empresarial, impõe ao consumidor o pagamento de "pacotes" com preços cada vez mais caros em razão do fato de que o valor pago a título de corrupção é repassado a terceiros.

No que concerne a importância no tema envolvendo a corrupção, na seara internacional, é importante destacar a doutrina elaborada por Aloísio Zimmer Junior, em face dos conceitos e preocupação que o assunto suscita.

Ao longo dos séculos $X X$ e $X X I$, conceituou-se a corrupção de diferentes modos, de acordo com a percepção que se teve do problema em cada contesto histórico apresentado. O Banco Mundial definiu corrupção como "abuso do cargo público para obtenção de ganhos privados" - ou abuso da função pública, para ser mais preciso e abrangente. Demonstrando compreensão semelhante sobre o tema, ao descrever a corrupção como 


\title{
Personalidade Acadêmica Homenageada: \\ Carlos Aurélio Mota de Souza (Universidade Ibirapuera - UNIB)
}

\begin{abstract}
"abuso de autoridade ou confiança púbica para benefício privado", está o trabalho desenvolvido pelo Fundo monetário Internacional. Em realidade, ambos preenchendo de significado o conceito de corrupção dentro de parâmetros muito semelhantes. ${ }^{2}$
\end{abstract}

Organizações mundiais, entre as quais o Fórum Econômico Mundial estima que o custo da corrupção equivale a US\$ 2,6 trilhões por ano, o que corresponde a cerca de $5 \%$ do Produto Interno Bruto (PIB) global. No Brasil, o principal alvo de atos de corrupção estão sendo desvendados conforme avança a operação judicial da "lava jato".

Esse indicador revela o tamanho do desafio que as corporações, em todo mundo, têm enfrentado no combate ao envolvimento a atos ilícitos.

Em meio a escândalos de corrupção e ondas de manifestações, a Lei anticorrupção foi uma resposta aos clamores da sociedade, bem como para atender os compromissos internacionais assumidos pelo país no combate à corrupção.

De forma esparsa, a legislação brasileira oferta, em vários dos seus diplomas legais, severas regras de repressão a prática da corrupção, entre os quais, somente para citar os mais usuais, temos no Código Penal, a tipificação da corrupção passiva no art. $317^{3}$, da corrupção ativa no art. $333^{4}$, os crimes contra a ordem tributária, econômica e contra as relações de consumo na Lei no 8.137, de 27 de dezembro de 1990 , entre os quais se destaca a redação do art. 3ํ․

2 ZIMMER JÚNIOR, Aloísio. Corrupção e improbidade administrativa : cenários de risco e a responsabilização dos agentes públicos municipais. São Paulo : Thomson Reuters Brasil, 2018, p. 33. ${ }^{3}$ Art. 317 - Solicitar ou receber, para si ou para outrem, direta ou indiretamente, ainda que fora da função ou antes de assumi-la, mas em razão dela, vantagem indevida, ou aceitar promessa de tal vantagem: Pena - reclusão, de 2 (dois) a 12 (doze) anos, e multa. (Redação dada pela Lei ํo 10.763, de 12.11.2003) § 1ํ- A pena é aumentada de um terço, se, em conseqüência da vantagem ou promessa, o funcionário retarda ou deixa de praticar qualquer ato de ofício ou o pratica infringindo dever funcional. $\S 2^{\circ}$ - Se o funcionário pratica, deixa de praticar ou retarda ato de ofício, com infração de dever funcional, cedendo a pedido ou influência de outrem: Pena - detenção, de três meses a um ano, ou multa.

${ }^{4}$ Art. 333 - Oferecer ou prometer vantagem indevida a funcionário público, para determiná-lo a praticar, omitir ou retardar ato de ofício: Pena - reclusão, de 2 (dois) a 12 (doze) anos, e multa. (Redação dada pela Lei no 10.763 , de 12.11.2003). Parágrafo único - A pena é aumentada de um terço, se, em razão da vantagem ou promessa, o funcionário retarda ou omite ato de ofício, ou o pratica infringindo dever funcional.

${ }^{5}$ Art. $3^{\circ}$ Constitui crime funcional contra a ordem tributária, além dos previstos no Decreto-Lei $n^{\circ} 2.848$, de 7 de dezembro de 1940 - Código Penal (Título XI, Capítulo I): I - extraviar livro oficial, processo fiscal ou qualquer documento, de que tenha a guarda em razão da função; sonegá-lo, ou inutilizá-lo, total ou parcialmente, acarretando pagamento indevido ou inexato de tributo ou contribuição social; II - exigir, 


\section{Personalidade Acadêmica Homenageada:}

Carlos Aurélio Mota de Souza (Universidade Ibirapuera - UNIB)

$\mathrm{Na}$ órbita civil, a redação dos atos de improbidade administrativa, os quais em sua expressiva maioria trazem em seu bojo a referência expressão ou tácita da prática de atos de corrupção, assim descritos pela Lei ํo 8.429/92 em três espécies: atos de improbidade administrativa que importam enriquecimento ilícito (art. 9으, I a XII); atos de improbidade administrativa que causam prejuízo ao erário (art. 10, I a XIII); e atos de improbidade administrativa que atentam contra os princípios da Administração Pública (art. 11, I a VII).

Pode ainda, o ato de improbidade causar uma efetiva lesão ou um perigo de lesão à Administração Pública, constituindo-se numa figura típica penal. E também acontecer da conduta não tocar a esfera penal, remanescendo no ilícito administrativo, sujeitando-se o agente a sanções civis (reparação do dano) e administrativas (multa civil, proibição de contratar com os órgãos públicos, proibição de receber incentivos fiscais ou creditícios).

As primeiras discussões sobre a necessidade de uma lei "anticorrupção" surgiu ainda no ano de 2010. Um dos seus objetivos era o de atender um acordo firmado pelo Brasil com a OCDE - Organização para a Cooperação e Desenvolvimento Econômico, no qual os 36 países da entidade se comprometeram a criar legislações eficientes no combate à corrupção. Na seara legislativa o texto sofreu fortes resistências ficando sua tramitação prejudicada por mais de um ano até que um grupo de deputados conseguiu constituir uma comissão especial, que permitisse dar mais celeridade ao processo de tramitação.

A legislação foi aprovada em agosto de 2013 e colocada em vigor em janeiro de 2014 e o seu texto é comparável, como já referido, a textos semelhantes existentes nos Estados Unidos (Foreign Corrupt Practices Act ou FCPA) e no Reino Unido (Bribery Act).

solicitar ou receber, para si ou para outrem, direta ou indiretamente, ainda que fora da função ou antes de iniciar seu exercício, mas em razão dela, vantagem indevida; ou aceitar promessa de tal vantagem, para deixar de lançar ou cobrar tributo ou contribuição social, ou cobrá-los parcialmente. Pena reclusão, de 3 (três) a 8 (oito) anos, e multa. III - patrocinar, direta ou indiretamente, interesse privado perante a administração fazendária, valendo-se da qualidade de funcionário público. Pena - reclusão, de 1 (um) a 4 (quatro) anos, e multa. 


\section{Personalidade Acadêmica Homenageada:}

\section{Carlos Aurélio Mota de Souza (Universidade Ibirapuera - UNIB)}

É inegável a proximidade dos termos e a estrutura da "Lei Anticorrupção" brasileira com a lei estadunidense Foreign Corrupt Practices Act, que tem sua origem no emblemático caso Watergate, ocorrido na década de setenta nos Estados Unidos, até porque tanto lá quanto cá há uma proximidade prática digna de justificar esse paralelismo legislativo.

Cabe ressaltar, assim, o caso Watergate foi um dos maiores escândalos políticos que ocorreu nos Estados Unidos. Em junho de 1972, cinco homens foram presos por invadirem a sede do Comitê Nacional Democrata em um conjunto comercial chamado "Watergate" em Washington, DC. A investigação da invasão desencadeou uma série de abusos de poder pelo presidente Nixon e membros de seu gabinete e partido político.

Nos Estados Unidos O escândalo resultou na renúncia do Presidente Nixon e em acusações formais de 69 pessoas, 48 das quais foram condenadas a prisão. No Brasil, vinte anos depois o Brasil passou pelo processo de Impeachment do expresidente Fernando Collor de Mello, ressaltando ainda a diferença de que no Brasil ninguém acabou sendo preso.

Com a implementação da FCPA, o governo dos Estados Unidos começou a pressionar a internacionalização da luta contra a corrupção e a adoção pelos países de lei semelhante. E o resultado foi a ocorrência do fenômeno de anticorrupção, que foi extremamente benéfico para a comunidade internacional. Hoje, a maioria das principais economias reformaram suas legislações nesse sentido. Entre elas estão a legislação dos EUA (FCPA), obviamente, e as reformas ocorridas na Alemanha (1998), França (2000 e 2007), Japão (2005) e Reino Unido (UK Bribery o Act - 2010). Brasil, Rússia, China e Índia estão em processo de adaptação da estrutura legal.

É importante destacar por ser um truísmo o fato de que as práticas de corrupção sempre estiveram de alguma foram relacionadas no cotidiano brasileiro.

O Brasil ratificou três tratados internacionais sobre o assunto (OEA Convenção Interamericana de Combate à Corrupção, ONU - Convenção das Nações Unidas e OCDE - Organização para a Cooperação e Desenvolvimento Econômico) e, com a aprovação da Lei, espera-se a mudança do panorama no combate à corrupção, tão percebida no país. 


\section{Personalidade Acadêmica Homenageada:}

\section{Carlos Aurélio Mota de Souza (Universidade Ibirapuera - UNIB)}

De outro vértice o patamar, os percentuais, o montante em dinheiro, aliado as empresas envolvidas, as quais até então não pairava qualquer mácula que pudesse impor alguma nódua a lei anticorrupção se apresentou como de importância indelével.

De fato, a lei vem a ser um instrumento de reforço da ética nos negócios e exigirá mudanças na forma como as empresas se relacionam com o setor público, com a adoção de medidas que inibam atos de corrupção.

\section{PONTOS RELEVANTES QUE MERECEM DESTAQUE E QUE ESTÃOPRESENTES NA LEI № 12.846 DE 1ㅇ DE AGOSTO DE 2013}

Cabe ressaltar, de forma inicial, que o texto legal previsto na Lei 12.846, designada como lei anticorrupção, vem a estabelecer a responsabilidade objetiva em face das práticas perpetradas pelas empresas atingidas pelos seus contornos normativos. Assim estabelece 0 art. $1^{\circ}$ da citada Lei:

Art. 1‥ Esta Lei dispõe sobre a responsabilização objetiva administrativa e civil de pessoas jurídicas pela prática de atos contra a administração pública, nacional ou estrangeira.

A exemplo do que consta da redação do art. $37, \S 6^{\circ}$ da Constituição Federal e lei anticorrupção traz em seu legislativo a responsabilidade objetiva da pessoa jurídica. Por conseguinte, diante desta modalidade de responsabilidade a qual independe de prova de conduta culposa, sendo devida pela simples prática de ato ilícito contra a Administração Pública.

Destarte, ao Poder Público não assiste provar que uma empresa que se envolveu em um ato corrupto com agentes governamentais, se beneficiou desse ato. Para tanto, basta a prova de que a corrupção existiu para que ela possa ser punida. E, também, não adianta transferir a responsabilidade para um funcionário da empresa - o que costumava acontecer na maioria dos casos de corrupção, e deixar que ele seja o único a arcar com as consequências do problema. 


\section{Personalidade Acadêmica Homenageada:}

Carlos Aurélio Mota de Souza (Universidade Ibirapuera - UNIB)

Além da previsão constitucional da responsabilidade objetiva presente no art. 37 , $\S 6^{\circ 6}$, cumpre destacar, por amor acadêmico que os predicados inerentes a Responsabilidade Objetiva, estão presentes também em outros diplomas legais. A responsabilidade objetiva, inovação trazida pelo Código Civil de 2002, é prevista no parágrafo único do art. $927^{7}$.

Verificou-se que o critério da culpa, requisito para a responsabilidade subjetiva, se mostrou insuficiente diante da sociedade moderna e em constante evolução, que se tornou muito mais vulnerável aos riscos.

Segundo o doutrinador Silvio Rodrigues, "na responsabilidade objetiva a atitude culposa ou dolosa do agente causador do dano é de menor relevância, pois, desde que exista relação de causalidade entre o dano experimentado pela vítima e o ato do agente, surge o dever de indenizar, quer tenha este último agido ou não culposamente." 8

Contextualizando o nascimento da responsabilidade objetiva, vale transcrever as palavras de Silvio de Salvo Venosa:

Para a caracterização do dever de indenizar devem estar presentes os requisitos clássicos: ação ou omissão voluntária, relação de causalidade ou nexo causal, dano e, finalmente, culpa. No tocante especificamente à culpa, lembramos que a tendência jurisprudencial cada vez mais marcante é de alargar seu conceito. Surgiu, daí, a noção de culpa presumida, sob o prisma do dever genérico de não prejudicar. Esse fundamento fez também nascer a teoria da responsabilidade objetiva, presente na lei em várias oportunidades, que desconsidera a culpabilidade, ainda que não se confunda a culpa presumida com a responsabilidade objetiva.

Daí por que a insuficiência da fundamentação da teoria da culpabilidade levou à criação da teoria do risco, com vários matizes, a qual sustenta que o sujeito é

\footnotetext{
${ }^{6}$ Art. 37. A administração pública direta e indireta de qualquer dos Poderes da União, dos Estados, do Distrito Federal e dos Municípios obedecerá aos princípios de legalidade, impessoalidade, moralidade, publicidade e eficiência e, também, ao seguinte: (...) § $6^{\circ}$ As pessoas jurídicas de direito público e as de direito privado prestadoras de serviços públicos responderão pelos danos que seus agentes, nessa qualidade, causarem a terceiros, assegurado o direito de regresso contra o responsável nos casos de dolo ou culpa.

${ }^{7}$ Art. 927. Aquele que, por ato ilícito (arts. 186 e 187), causar dano a outrem, fica obrigado a repará-lo. Parágrafo único. Haverá obrigação de reparar o dano, independentemente de culpa, nos casos especificados em lei, ou quando a atividade normalmente desenvolvida pelo autor do dano implicar, por sua natureza, risco para os direitos de outrem.

${ }^{8}$ RODRIGUES, Silvio. Responsabilidade civil. São Paulo: Saraiva, 2003. p. 237.
} 


\section{Personalidade Acadêmica Homenageada:}

Carlos Aurélio Mota de Souza (Universidade Ibirapuera - UNIB)

responsável por riscos ou perigos que sua atuação promove, ainda que coloque toda diligência para evitar o dano.

Trata-se da denominada teoria do risco criado e do risco benefício. O sujeito obtém vantagens ou benefícios e, em razão dessa atividade deve indenizar os danos que ocasiona. Em síntese, cuida-se da responsabilidade sem culpa em inúmeras situações nas quais sua comprovação inviabilizaria a indenização para a parte presumivelmente mais vulnerável.

Em um primeiro momento é possível imaginar que a aplicação da responsabilidade objetiva nos moldes da responsabilidade Objetiva se apresente como sendo prejudicial aos interesses da empresa, pois essas podem ser injustiçadas em razão da atitude desonesta de um único funcionário, por exemplo. Todavia, a afirmação não se justifica pelo fato de que essa organização fará com que seu departamento de compliance e boas práticas seja instituído.

Por sua vez, dentro de um aspecto de responsabilidade pessoal a lei anticorrupção trata o tema da responsabilidade de forma subjetiva, assim, a responsabilização da pessoa natural que participou do ato ilícito depende da comprovação de culpa, conforme depreende-se do artigo 3 da Lei:

Art. $3^{\circ}$ A responsabilização da pessoa jurídica não exclui a responsabilidade individual de seus dirigentes ou administradores ou de qualquer pessoa natural, autora, coautora ou partícipe do ato ilícito. $\S 1^{\circ}$ A pessoa jurídica será responsabilizada independentemente da responsabilização individual das pessoas naturais referidas no caput. $\S 2^{\circ}$ Os dirigentes ou administradores somente serão responsabilizados por atos ilícitos na medida da sua culpabilidade.

Se a responsabilidade da empresa é objetiva, os seus agentes são responsabilizados na modalidade de culpa, o que é pertinente em face da proximidade da realidade fática com a conduta do agente que só vem a reforçar a necessidade improrrogável do compliance.

Destarte, a responsabilidade objetiva é o pilar central da lei anticorrupção brasileira, a possibilidade do acordo de leniência por parte das empresas é tida como um dos aspectos mais importantes para a eficácia da sua aplicação. 


\section{Personalidade Acadêmica Homenageada:}

\section{Carlos Aurélio Mota de Souza (Universidade Ibirapuera - UNIB)}

O acordo de leniência é um compromisso assumido pela pessoa jurídica de colaborar com as investigações e, através dele, a empresa pode ter o benefício de uma série de atenuantes nas sanções, desde que preenchidas as seguintes condições: confissão no envolvimento do ilícito e manifestação voluntária em cooperar de forma plena e permanente nas investigações, de forma a permitir o acesso a informações e documentos necessários para o deslinde da causa, bem como cessar completamente a participação na ilicitude.

No que se refere às sanções, a lei é bastante severa. Na esfera administrativa, estão previstas multas no valor de $0,1 \%$ a $20 \%$ do faturamento bruto do último exercício anterior ao da instauração do processo administrativo, a qual nunca será inferior à vantagem auferida e publicação extraordinária da decisão condenatória. Quando não for possível calcular o montante do faturamento bruto, a Lei prevê a aplicação de multa no valor de $\mathrm{R} \$ 6$ mil a $\mathrm{R} \$ 60$ milhões.

$\mathrm{Na}$ esfera jurídica, as sanções consistem em perdimento de bens, direitos ou valores que representem vantagem ou proveito direta ou indiretamente obtidos da infração, suspensão ou interdição parcial de suas atividades, dissolução compulsória da pessoa jurídica e proibição de receber incentivos, subsídios, subvenções, doações ou empréstimos de órgãos ou entidades públicas e de instituições financeiras públicas ou controladas pelo poder público.

Todavia, de acordo com 0 art. $7^{\circ}$ da Lei, no momento da aplicação das sanções, as autoridades levarão em conta a existência de mecanismos e procedimentos internos, auditoria e incentivo à denúncia de irregularidades e aplicação efetiva de códigos de ética e de conduta no âmbito da organização. Novamente a importância do compliance se torna ainda mais evidente.

Cabe ressaltar outro ponto relevante da lei referem-se à abrangência de sua aplicação, tanto pela União, Estados e Municípios. Ademais, ela não se restringe ao país, podendo ser aplicada a empresas brasileiras atuando no exterior.

A lei anticorrupção ainda oferta uma ampla possibilidade de responsabilizar uma empresa envolvida, tendo em vista que a mesma pode alcança-la após a sua alteração societária, pois em seus termos estabelece a responsabilidade das empresas adquirentes nos casos de alteração contratual, transformação, fusão ou 


\section{Personalidade Acadêmica Homenageada:}

\section{Carlos Aurélio Mota de Souza (Universidade Ibirapuera - UNIB)}

cisão societária. Em outras palavras, a legislação brasileira estabelece que, ao adquirir participação societária em uma determinada sociedade, a sociedade adquirente pode responder por violações à legislação anticorrupção praticadas pela sociedade adquirida, antes da consumação da operação.

Portanto, estão aí os motivos que levarão as empresas brasileiras, especialmente as que atuam em setores mais regulados ou com grande atuação no setor público, a entenderem a necessidade vital de implementarem um bom programa de compliance, a fim de criarem uma cultura de ética e responsabilidade social.

\section{BOAS PRÁTICAS OU COMPLIANCE}

A nova lei não obriga as empresas de estabelecerem sistemas preventivos anticorrupção no controle interno de suas atividades. Todavia, seu rigor, agravado pela regra da responsabilidade objetiva gera elevados riscos às organizações, impondo a elas a necessidade de se precaverem. Primeiro, no sentido de prevenir a ocorrência de desvios. Segundo, caso eles ocorram, o sistema preventivo servirá de atenuante quanto à aplicação das multas, conforme já exposto.

Como sinônimo de boas práticas empresariais o compliance, termo em inglês muito em voga, pode ser definido como o conjunto de procedimentos adotados por uma empresa visando detectar, prevenir e combater fraudes e infrações às leis e regulamentos aplicáveis às suas atividades, bem como assegurar que seus valores e padrões de conduta sejam observados por seus colaboradores (administradores, empregados, fornecedores etc.).

O Compliance é um dos pilares básicos da Governança Corporativa, pois ao mesmo tempo em que aprimora continuamente o sistema de controles internos da empresa, promove a cultura de conformidade com as regulamentações e legislações aplicáveis, às políticas internas e ao código de conduta e ética da organização.

A existência de um programa de compliance em uma empresa demonstra comprometimento com a ética e a integridade na prática de seus negócios, fazendo com que ela seja vista de forma diferenciada pelo mercado. 


\section{Personalidade Acadêmica Homenageada:}

\section{Carlos Aurélio Mota de Souza (Universidade Ibirapuera - UNIB)}

Em termos práticos, um bom programa de compliance deve ter, pelo menos uma estrutura definida a partir de um mapeamento dos riscos, a qual está encarregada em desenvolver um a análise criteriosa sobre as transações concretizadas ou a concretizar da empresa, com o intuito de evitar que condutas indesejadas sejam formuladas, o que vem a macular a imagem da empresa. Por sua vez, a instituição e consolidação de um Código de conduta, o qual traz em seu bojo a "missão" da empresa e os seus princípios de gestão, não havendo a possibilidade de seus colaboradores alegarem ignorância da sua existência, quando bem aplicado e divulgado. A questão do treinamento de boas práticas é outra questão que se sobressai, ainda mais diante das análises de mercado, de postura e de boas práticas desenvolvidas pela empresa. Neste pensar é imprescindível o comprometimento da alta administração, pois essa é reflete aos demais escalões da empresa o modo de agir, de pensar e portar da própria empresa. Aliado a todas essas questões, outra é digna de destaque, voltada a sistêmica avaliação de eficácia (critérios de métricas definidos).

Sem nenhuma importância a adoção das práticas citadas acima se não estiverem associadas a adequações evolutivas dentro de uma visão moderna de gestão. Por seu turno, aos integrantes da empresa é indispensável à apresentação de um canal de comunicação, o qual assegure o sigilo do informante, para que as denúncias sejam levadas ao conhecimento da diretoria, ou ouvidoria, mas que não fiquem a margem de qualquer investigação ou mesmo da aplicação das necessárias sanções diante de transgressões.

É importante a criação de um código de conduta amplamente divulgado, seguido de treinamento para os funcionários. É ainda interessante criar e revisar os programas de Compliance para adequar a realidade da empresa com as exigências da nova lei. É preciso ter especial atenção aos elementos mais críticos como: contribuições políticas, pagamentos de facilitação, terceiros que interagem com o governo em nome da empresa e autorizações para pagamento e recebimento de brindes e presentes. Funcionários em posições de risco, que têm contato com o setor público, devem ser treinados e preparados para lidar com situações, como pedidos de propina. 


\section{Personalidade Acadêmica Homenageada:}

\section{Carlos Aurélio Mota de Souza (Universidade Ibirapuera - UNIB)}

A lei prevê punição de pessoas que se envolvem em práticas de atos de corrupção em nome ou benefício de uma empresa contratante. Por isso, o monitoramento mais próximo e efetivo de fornecedores, terceiros e parceiros é cada vez mais relevante na gestão do risco de corrupção.

É necessário estabelecer critérios mais rigorosos nas operações de avaliação de contratos e nas operações de vendas, principalmente voltados a investigar prévias ilegalidades contra a administração pública.

É de extrema importância a existência de uma auditoria interna, a fim de reforçar os mecanismos de monitoramento quanto ao cumprimento da Lei. Portanto, deve-se criar e fomentar uma cultura de compliance anticorrupção dentro da empresa, elaborando treinamentos e dando suporte à liderança com exemplos práticos.

As sanções estabelecidas pela Lei Anticorrupção, por si só, já justificam a aplicação efetiva e imediata de programas de Compliance. Mas, não se pode perder de vista que a medida alimenta também um ciclo virtuoso, que melhora a concorrência e a imagem do Brasil, dentro e fora do país. Os processos de Compliance adicionam valor à marca de qualquer empresa, porque a ética nos negócios é um diferencial de mercado e proporciona segurança a acionistas, dirigentes, empregados e investidores.

Além disso, um ambiente corporativo saudável, no qual as normas são cumpridas e não há espaço para atos ilícitos, gera produtividade e os próprios funcionários ganham tranquilidade ao servir uma empresa livre de corrupção. E, indo além: uma vez que um dano de imagem e reputação é causado à uma empresa, pode haver uma perda intangível no seu valor.

De uma forma geral, o compliance não é muito difundido nas empresas locais. São raras as empresas $100 \%$ brasileiras que operam algo desta natureza. Todavia, com a promulgação da lei, empresários já avaliam como adequar suas operações para essa nova realidade.

Para o Secretário da CGU (Controladoria Geral da União), órgão responsável por aplicar a lei na esfera federal, o impacto da nova lei transcende a questão ética e moral, propondo ainda a concorrência limpa. Um ambiente com menos corrupção gera mais competição e vitória de quem tem mais capacidade técnica para atuar. As 


\section{Personalidade Acadêmica Homenageada:}

\section{Carlos Aurélio Mota de Souza (Universidade Ibirapuera - UNIB)}

empresas têm que estar mais preparadas para serem competitivas, produzindo melhor e por melhores preços. A corrupção é um dos maiores fatores de distração da economia, pois, se alguém paga suborno é porque provavelmente não tem o melhor produto, ou o mais barato.

Portanto, além da questão ética e moral, a lei propõe a eficiência no ambiente empresarial.

A lei, inclusive, pode impactar em outros campos da economia, como no mercado de crédito. As instituições financeiras, ao emprestar recursos para empresas que negociam com o poder público, levarão em conta a integridade da empresa.

Organizações sem esses mecanismos vão pagar um preço mais alto, pois aquelas punidas por atos corruptos correm maiores riscos de incorrerem à falência.

Portanto, o momento oferece aos empresários um conselho: adaptem-se às inovações trazidas pela Lei Anticorrupção, implantando suas ferramentas e mecanismos de prevenção e planejamento estratégico, evitando-se, no futuro, alguma surpresa indesejada.

A título de exemplo, a Petrobrás, recentemente envolvida na chamada Operação Lava Jato, um dos maiores esquemas de corrupção do país, luta agora para reestruturar a sua operação e instituir um novo modelo de compliance. Além da substituição da presidência e de toda a diretoria executiva realizada em fevereiro de 2015, a companhia vem implementando uma série de medidas e criando novos órgãos internos para melhorar seus mecanismos de combate à corrupção.

Dessa forma, a criação de sistemas de compliance será um agente de mudanças dentro e fora das companhias, pois também irão impactar na sociedade de forma positiva, gerando mais produtividade e até um PIB maior para o Brasil.

\section{PONTOS CONTROVERTIDOS PRESENTES NA LEI ANTICORRUPÇÃO}

O ponto nebuloso da lei, e bastante criticado, concentra-se no art. $8^{\circ}$, que dispõe que "a instauração e o julgamento de processo administrativo para apuração 


\section{Personalidade Acadêmica Homenageada:}

\section{Carlos Aurélio Mota de Souza (Universidade Ibirapuera - UNIB)}

da responsabilidade de pessoa jurídica cabem à autoridade máxima de cada órgão ou entidade dos Poderes Executivo, Legislativo e Judiciário".

Tal disposição gera a preocupação de que as autoridades de cada local apliquem a legislação de forma arbitrária ou abusiva em relação às penalidades.

A falta de um órgão centralizado ou uma autoridade especializada para aplicar a lei de forma consistente nos diversos entes federativos promoverá uma enorme pulverização - o Brasil tem mais de 5.500 municípios, sendo que em cada um deles têm-se uma câmara de vereadores. Com a aplicação consistente da lei por um órgão centralizado, chega-se aos parâmetros de aplicabilidade, trazendo uma maior segurança jurídica.

Para o criminalista Marcelo Leal, "a Lei Anticorrupção pode gerar insegurança jurídica na medida em que o processo administrativo será decidido pela autoridade máxima do órgão que o instaurou, cargo normalmente ocupado por pessoas nomeadas politicamente".

$\mathrm{Na}$ avaliação de Leal, existe risco de que a lei seja usada para atender interesses políticos ou corporativos. "Como existe um alto grau de subjetividade na definição do ato de corrupção, a autoridade responsável pelo julgamento pode aliviar" para um aliado político ou forçar a condenação de um inimigo. O mais curioso é que a própria Organização para Cooperação e Desenvolvimento Econômico alerta que quanto maior a concentração de poder nas mãos de uma única pessoa, maior a chance da prática de corrupção. Ou seja, a lei que foi criada para combater a corrupção traz em seu bojo o próprio germe daquilo que pretende coibir", alerta.

A luz no fim do túnel é que o parágrafo $1^{\circ}$ do art. $8^{\circ}$ prevê a possibilidade de delegação da competência, o que abre a possibilidade de que, por meio de convênios, haja a concentração de competência em um número menor de autoridades, permitindo que atuem com imparcialidade e que desenvolvam maior especialização.

Se na esfera federal tem-se a CGU, com alto nível de articulação e profissionais altamente gabaritados, de outro lado existem milhares de prefeituras que não têm sequer um departamento jurídico. São realidades completamente diferentes. 


\section{Personalidade Acadêmica Homenageada:}

\section{Carlos Aurélio Mota de Souza (Universidade Ibirapuera - UNIB)}

A Constituição Federal não prevê regra específica que defina a modelagem das atividades do sistema de controles internos das diversas esferas federativas do País.

Nesse contexto, a PEC 45/2009 trouxe normas claras sobre a organização dessas atividades, razão pela qual se faz necessário avançar com a proposta, fortalecendo e dando maior autonomia aos órgãos de controle interno.

Ademais, a questão da responsabilidade objetiva trazida pela Lei é vista como injusta para alguns, que argumentam que a lei não permite que uma empresa demonstre e comprove a sua boa fé, e ainda, que tenha tomado todas as medidas de prevenção e combate à ilicitude nos negócios.

Nesse seara, criticam a falta de clareza quanto aos parâmetros de avaliação dos programas de compliance, já que a lei é subjetiva nesse sentido.

Outro ponto que a lei deixou de esclarecer diz respeito a empresas declaradas inidôneas pelo governo federal; se elas podem contratar com estados e municípios.

Embora a lei mencione a existência de um cadastro nacional, ela não esclarece se uma empresa inidônea em um ente federativo está proibida de transacionar com todos os entes federativos.

Certo é que essas dúvidas emanadas da Lei serão sanadas quando da aplicação aos casos concretos, sendo que a jurisprudência será criada ao longo do tempo, até ser aplicada de maneira efetiva e conforme. Para tanto, será necessário um trabalho firme e contínuo dos órgãos de fiscalização e a profissionalização destes.

\section{CONCLUSÃO}

A corrupção torna o país menos desenvolvido, o serviço público ineficiente, a concorrência de mercado é destruída, reduz os investimentos e, consequentemente, o crescimento econômico.

O objetivo da Lei oㅡ 12.846/2013 é combater esse problema que assombra o Brasil, principalmente nos dias de hoje, através de desestímulos das práticas ilícitas 


\section{Personalidade Acadêmica Homenageada:}

\section{Carlos Aurélio Mota de Souza (Universidade Ibirapuera - UNIB)}

por parte de empresas privadas que se relacionam com o poder público, a fim de proporcionar maior segurança e integridade no mercado econômico.

A promulgação da lei anticorrupção brasileira evidencia a evolução do país no âmbito empresarial, pois a legislação exige profundas mudanças tanto das políticas organizacionais quanto na mentalidade do empresariado.

A partir de agora a empresa é a maior interessada em prevenir os desvios e, ainda, a incentivar as denúncias internas, haja vista as rigorosas proposições da lei.

Portanto, espera-se que as organizações invistam em bons programas de compliance. Além de afetar a sociedade empresarial, é inegável dizer que a lei irá afetar a sociedade como um todo, já que esta clama pelo fim da corrupção. De fato a lei é mais uma ferramenta no combate às práticas ilícitas.

O que se espera é que a efetividade da lei anticorrupção brasileira, aliada ao recrudescimento das sanções aos atos de corrupção identificados, façam com que as empresas, nacionais e multinacionais, preocupem-se cada vez mais com a higidez de seus negócios, implementando programas de compliance eficazes. Só assim será possível alterar-se a realidade corrupta.

Certo é que o seu resultado dependerá de sua efetiva aplicação e fiscalização. Se positivo, acredita-se que a lei irá mudar o panorama do combate à corrupção no Brasil e irá se alcançar a era da empresa limpa. Resta-nos agora, esperar.

\section{REFERÊNCIAS}

CAMPOS, Patrícia Toledo de. Comentários à Lei no 12.846/2013. Rio de Janeiro : Rideel. 2013

FARIA, Felipe. Programas de compliance ganham importância com a nova Lei Anticorrupção. São Paulo: Método, 2014.

GIEREMEK, Rogéria. Lei Anticorrupção e Programas de Compliance. Rio de Janeiro: Forense, 2018

GUIMARÃES, Deocleciano Torrieri. Dicionário Universitário Jurídico. Rio de Janeiro : Rideel. 2013. 
Personalidade Acadêmica Homenageada:

Carlos Aurélio Mota de Souza (Universidade Ibirapuera - UNIB)

HAGE, Jorge. Lei Anticorrupção vai mudar a atitude do empresariado brasileiro. Disponível em: http://www.cartacapital.com.br/politica/lei-anticorrupcao-vaimudaratitude-e-mentalidade-do-empresariado-brasileiro201d-2906.html. Acesso em 13/10/2018.

JAROLETO, Jair. Advogados alertam para efeito inverso da lei anticorrupção. Disponível em: http://www.conjur.com.br/2013-nov-19/especialistas-alertam-riscoleianticorrupcao-efeito-inverso. Acesso em 13/10/2018.

LEMOR JÚNIOR, Arthur. Nova lei anticorrupção. Disponível em: www.cartacapital.com.br/blogs/blog-do-serapiao/201ce-mais-uma-ferramentaparacombater-a-criminalidade-economica-organizada201d-diz-promotor-826.html. Acesso em 13/10/2018.

MAGALHÃES, João Marcelo Rego. Aspectos relevantes da lei anticorrupção empresarial brasileira (Lei no 12.846/2013). Disponível em: http://www.tce.ce.gov.br/component/jdownloads/finish/347-revista-controle-volumexin-2-dezembro-2013/2290-artigo-2-aspectos-relevantes-da-lei-anticorrupcao empresarial-brasileira-lei-n-12-846-2013? Itemid=592. Acesso em 13/10/2018.

PENA, Eduardo Chemale Selistre. Punição às empresas é diferencial da Lei Anticorrupção. Disponível em: http://www.conjur.com.br/2013-set-26/eduardopenapunicao-empresas-diferencial-lei-anticorrupcao. Acesso em 13/10/2018.

RODRIGUES, Silvio. Responsabilidade civil. São Paulo: Saraiva, 2003.

SANTOS JÚNIOR, Belisário dos; PARDINI, Isabella Leal. Lei Anticorrupção gera incertezas, mas consolida a necessidade do compliance. Disponível em: http://interessenacional.uol.com.br/index.php/edicoes-revista/lei-anticorrupcaogeraincertezas-mas-consolida-a-necessidade-do-compliance/. Acesso em 13/10/2018.

SANTOS, Renato Almeida dos. Compliance como ferramenta de mitigação e prevenção da fraude organizacional. Disponível em: https://www.editoraroncarati.com.br/v2/phocadownload/compliance ferramenta mitig acao.pdf. Acesso em 13/10/2018.

SELHORST, Fábio. Lei Anticorrupção reforça importância do compliance. Disponível em: http://www.conjur.com.br/2014-fev-21/fabio-selhorst-leianticorrupcaoreforca-importancia-compliance. Acesso em 13/17/2018.

VENOSA, Sílvio de Salvo. A responsabilidade objetiva no novo Código Civil. Disponível em: $\quad$ http://www.migalhas.com.br/dePeso/16,Ml916,11049A+responsabilidade+objetiva+no+novo+Codigo+Civil. Acesso em 13/10/2018. 
Personalidade Acadêmica Homenageada:

Carlos Aurélio Mota de Souza (Universidade Ibirapuera - UNIB)

ZIMMER JÚNIOR, Aloísio. Corrupção e improbidade administrativa: cenários de risco e a responsabilização dos agentes públicos municipais. São Paulo : Thomson Reuters Brasil, 2018, 